\title{
Genistein Improves the Major Depression through Suppressing the Expression of miR-221/222 by Targeting Connexin 43
}

\author{
Fang Shen ${ }^{1}$, Wan-li Huang ${ }^{1}$, Bao-ping Xing ${ }^{1}$, Xiang Fang², Mei Feng ${ }^{3}$, and Chun-ming Jiang ${ }^{3} \bowtie$ \\ ${ }^{1}$ Department of Psychiatry, Tongde Hospital of Zhejiang Province, Hangzhou, China \\ ${ }^{2}$ Department of Clinic Lab, Hangzhou First People's Hospital, Nanjing Medical University, the Fourth Clinical Medical College \\ of Zhejiang Chinese Medicine University, Hangzhou, China \\ ${ }^{3}$ Department of Pediatrics, Hangzhou First People's Hospital, Nanjing Medical University, the Fourth Clinical Medical College \\ of Zhejiang Chinese Medicine University, Hangzhou, China
}

\begin{abstract}
Objective Recent studies have indicated the possibility that genistein may improve depression via regulating the expression of miR$221 / 222$. This study is to explore whether genistein could improve depression by altering miR-221/222 levels and investigate the possible mechanisms involved in the improvement effect of genistein.

Methods The animal model of depression was established through unpredictable chronic mild stress. Nest building test and splash test were adapted to evaluate the effects of genistein on depressive symptoms in mice. qRT-PCR and western blot analysis were used to detect the expression of miR-221/222 and connexin $43(\mathrm{Cx} 43)$ in the prefrontal cortex of the mice. In vitro, U87-MG astrocytes were treated with genistein and the expression of miR-221/222 and Cx43 was measured. The dual-luciferase reporter assay was used to verify whether Cx43 was a direct target of miR-221/222.

Results The behavioral tests showed that genistein could significantly reduce depression symptoms of mice, and this remission was not affected by gender. Genistein in vivo and in vitro could reduce increased levels of miR-221 and miR-222 in the prefrontal cortex of depressed mice, while upregulate $\mathrm{Cx} 43$ expression. Dual-luciferase reporter assay suggested Cx43 was directly regulated by miR-221/222 in astrocytes.
\end{abstract}

Conclusion Genistein can play its antidepressant effect through down-regulating miR-221/222 by targeting Cx43.

Psychiatry Investig 2018;15(10):919-925

Key Words Genistein, Major depression, miR-221/222, Cx43.

\section{INTRODUCTION}

Major depression is a complex mental disorder characterized by physiological, affective, and cognitive impairments that lead to maladaptive behavior. It is a major public health concern which affects about $2-3 \%$ people worldwide. This disease is predicted to become the second leading cause of disability by 2,020 according to the World Health Organiza-

\footnotetext{
Received: March 14, 2018 Revised: June 4, 2018

Accepted: June 29, 2018

$\bowtie$ Correspondence: Chun-ming Jiang, MD

Department of Pediatrics, Hangzhou First People's Hospital, Nanjing Medical University, the Fourth Clinical Medical College of Zhejiang Chinese Medicine University, No. 261 Huansha Road, Shangcheng District, Hangzhou 310003, China

Tel: +86-571-56005600, Fax: +86-571-56005600

E-mail: cmjiang@njmu.edu.cn

(a) This is an Open Access article distributed under the terms of the Creative Commons Attribution Non-Commercial License (https://creativecommons.org/licenses/bync/4.0) which permits unrestricted non-commercial use, distribution, and reproduction in any medium, provided the original work is properly cited.
}

tion. ${ }^{1,2}$ The high lifetime prevalence of this disabling condition, coupled with limitations in existing medications, make necessary the development of improving the therapeutics.

Genistein, a dietary isoflavone from soy, has been widely studied due to its effects on cancer, osteoporosis and cardiovascular diseases, as well as its use to attenuate depressive symptoms. ${ }^{3-5}$ In these studies, genistein was proved to have the ability of improving the quality of life and depressive symptoms in postmenopausal osteoporosis women. However, the mechanism of the effect of genistein on depression is still unclear.

Recently, more and more researchers paid attention to the effects of microRNAs on the pathophysiology of depression and their contribution to the action of antidepressants..$^{6-8}$ Some clinical and experiment researches showed that miR-221 was found significantly increased in the prefrontal cortex, cerebrospinal fluid and serum in depressed patients. ${ }^{910}$ In addition, the antidepressant treatment can significantly reduce the expression of miR-221/222 in depressed cell model and 
patients, ${ }^{11,12}$ which suggesting that miR-221/222 may involve the occurrence of depression. Interestingly, some studies have reported genistein could work in cells by down-regulating miR221/222 expression. ${ }^{13}$ Therefore, we speculate that genistein may play its antidepressant role by regulating miR-221/222 expression. Further, bioinformatics research indicates that connexin $43(\mathrm{Cx} 43)$ is a target of miR-221/222, ${ }^{14}$ while the expression of $\mathrm{Cx} 43$ is closely related to depression. ${ }^{15}$ Thus, it indicates that genistein may improve depression through regulating miR221/222 expression and targeting Cx43.

In conclusion, we proposed to examine whether genistein could improve depression by regulating the expression levels of miR-221/222 and targeting Cx43 in this article. Besides, the effect of gender on genistein's antidepressant activity was also studied.

\section{METHODS}

\section{Establishment of the depression model and behavior tests}

The depressive animal model referred to the reference of Nollet et al. ${ }^{16}$ Briefly, BALB/c mice ( 8 weeks) were divided to three groups (normal, vehicle and genistein) in the experiment. The normal group was non-UCMS treated mice. The mice were placed in cages with a stable environment (inverted $12 \mathrm{~h}$ light/dark cycle, temperature $22 \pm 1^{\circ} \mathrm{C}$, humidity 55 $\pm 10 \%)$ and the UCMS regimen lasted 9 weeks. Genistein (5 $\mathrm{mg} / \mathrm{kg} /$ day) and vehicle (DMSO) intraperitoneal administration began after two weeks of UCMS and continued until the end of the experiment. On the eighth week, behavioral tests (nest building test and splash test) were initiated and evaluated using the following methods.

\section{The nest building test}

1) As the stressed mice have been already individually housed, we isolated non-UCMS mice in clean individual cages for $24 \mathrm{~h}$ before the test;

2) One hour before the beginning of the dark phase (active period), we placed a cotton nest let in each cage;

3) The nest quality was evaluated using the following criteria:

Score 1: The cotton square is intact.

Score 2: The cotton square is partially used.

Score 3: The cotton is scattered but there is no form of nest.

Score 4: The cotton is gathered but there is no nest ("flat nest").

Score 5: The cotton is gathered into a "ball" with a small passage for entry of the animal (as an igloo, with or without roof).

\section{The splash test}

1) A mouse was placed in the "splash cage";

2) With the sprayer, we splashed the back of the mouse with a high viscosity $10 \%$ sucrose solution to stimulate grooming behavior, and quickly placed the mouse back into its home cage;

3) We measured the latency to initiate the first grooming behavior, as well as the frequency and duration of grooming over a 5-min period. We started the stopwatch when the mouse was returned to its home cage immediately after being splashed with $10 \%$ sucrose solution.

The details of animal experimental design are shown in Figure 1A. The study was approved by Ethics Committee of Hangzhou First People's Hospital, Nanjing Medical University, the Fourth Clinical Medical College of Zhejiang Chinese Medicine University (Hangzhou, China).

\section{Cell culture and treatment}

Human U87-MG, a primary glioblastoma cell line, was provided by American Type Culture Collection (ATCC). The cells were cultured in Dulbecco's modified Eagle's medium (DMEM) (Gibco, Carlsbad, CA, USA) supplemented with $10 \%$ fetal bovine serum (FBS) (Gibco BRL, Gaithersburg, MD, USA), $2 \mathrm{mM}$ glutamine, $100 \mu \mathrm{g} / \mathrm{mL}$ streptomycin and 100 units $/ \mathrm{mL}$ penicillin (Hyclone, Logan, UT, USA) at $37^{\circ} \mathrm{C}$ in a humidified (5\% $\mathrm{CO}_{2}, 95 \%$ air) atmosphere. The vehicle and genistein $(10 \mu \mathrm{M})$ solutions were freshly prepared and applied to cultured cells.

\section{RNA extraction and quantitative real-time polymerase chain reaction}

Total RNA was extracted from prefrontal cortex of mice and cultured cells using an RNeasy mini kit or miRNeasy Mini Kit (Qiagen, Valencia, CA, USA) according to the manufacturer's instruction. MiR-221/222 expressions were measured by quantitative real-time PCR (qRT-PCR) using an Applied Biosystems 7,500 Fast Sequence Detection System (Applied Biosystems Inc., Carlsbad, CA, USA) and genespecific Taqman assay kits (Applied Biosystems Inc.). GAP$\mathrm{DH}$ and U6 expression were served as loading controls for Cx43 and miR-221/222, respectively. The primers of miR221/222 and Cx43 are listed in Table 1 and 2. Cycling conditions were as follows: $95^{\circ} \mathrm{C}$ for $10 \mathrm{~min}$ and 40 cycles of $15 \mathrm{~s}$ at $95^{\circ} \mathrm{C}$ and $60 \mathrm{~s}$ at $60^{\circ} \mathrm{C}$.

\section{Western blot analysis}

The protein levels of $\mathrm{Cx} 43$ in prefrontal cortex of treated mice and U87-MG cells transfected with As-miR-221/222 were detected by western blot analysis. The protein $(40 \mu \mathrm{g})$ was electrophoresed in 10\% SDS-PAGE (Thermo Fisher Scientif- 
Table 1. List of primers used for qRT-PCR in cell model

\begin{tabular}{lll}
\hline \multicolumn{1}{c}{ Primers } & \multicolumn{1}{c}{ Forward } & \multicolumn{1}{c}{ Reverse } \\
\hline miR-221 & 5'-GCTACATTGTCTGCTGGGTTTCA-3' & 5'-AGCTTTCTTGCGGTCCTTTCTCTG-3' \\
miR-222 & 5'-TCTGGCTACTGGGTCTCTGATG-3' & 5'-TCCTCCCCCTTGTAGTATTGAA-3' \\
Cx43 & 5'-CCCCACTCTCACCTATGTCTCC-3' & 5'-ACTTTTGCCGCCTAGCTATCCC-3' \\
GAPDH & 5'-GGGAGCCAAAAGGGTCATCATCTC-3' & 5'-CCATGCCAG TGAGCTTCCCGTTC-3' \\
U6 & 5'-CGCTTCGGCAGCACATATAC-3' & 5'-TTCACGAATTTGCGTGTCAT-3' \\
\hline
\end{tabular}

Table 2. List of primers used for qRT-PCR in animal model

\begin{tabular}{lll}
\hline \multicolumn{1}{c}{ Primers } & \multicolumn{1}{c}{ Forward } & \multicolumn{1}{c}{ Reverse } \\
\hline miR-221 & 5'-AGCUACAUUGUCUGCUGGGUUUC-3' & 5'-AACCCAGCAGACAAUGUAGCUUU-3' \\
miR-222 & 5'-AGCUACAUCUGGCUACUGGGU-3' & 5'-CCAGUAGCCAGAUGUAGCUUU-3' \\
Cx43 & 5'-CCCCACTCTCACCTATGTCTC-3' & 5'-ACTTTTGCCGCCTAGCTATCC-3' \\
GAPDH & 5'-GTGCTGAGTATGTCGTGGAGTC-3' & 5'-CAGTTGGTGGTACAGGAGGC-3' \\
U6 & 5'-CTCGCTTCGGCAGCACATATACT-3' & 5'-ACGCTTCACGAATTTGCGTGTC-3' \\
\hline
\end{tabular}

ic, Waltham, MA, USA) and transferred to PVDF membrane at $75 \mathrm{~mA}$ overnight at $4^{\circ} \mathrm{C}$. Next day, the PVDF membrane was blocked and incubated with 1:500 anti-Cx43 rabbit monoclonal antibody (Sigma-Aldrich, St-Louis, MO, USA) overnight at $4^{\circ} \mathrm{C}$. The secondary antibody was goat anti-rabbit IgGHRP (Sigma-Aldrich) diluted 1:2,500 in fresh blocking solution for $2 \mathrm{~h}$ at room temperature. $\alpha$-tubulin was used as an endogenous control to normalized expression data. Protein expression was measured and quantified using image analysis system (Image Quant LAS 4,000 mini).

\section{Luciferase activity assay}

To test whether the Cx43 is a direct target gene of miR-221/ 222, the human 3'-UTR segment of wild-type Cx43 gene was amplified and cloned into the pGL3/luciferase vector (Promega, Madison, WI, USA). The mutant 3'-UTR of Cx43 mRNA was obtained by replacing the predicted miRNA binding site sequence. U87-MG cells were plated into 24 -well plates $(3 \times$ $10^{4}$ cells/well). After 24 hours, cells were co-transfected with 800 ng luciferase vector, including the 3'-UTR of Cx43 and miRNA-221/222 mimic at a final concentration of $100 \mathrm{nM}$ with Lipofectamine 2,000. Luciferase activity was measured $72 \mathrm{~h}$ after being transfected by the Dual-Luciferase Reporter Assay System (Promega).

\section{Statistical analysis}

All experiments were carried out in triplicates and presented as mean \pm standard errors. Statistical analysis was performed using SPSS version 17.0 software (SPSS Inc., Chicago, IL, USA). $\mathrm{p}<0.05$ was considered significant and $\mathrm{p}<0.01$ was considered highly significant.

\section{RESULTS}

\section{Genistein treatment improves depressive symptoms of UCMS mice}

The unpredictable chronic mild stress (UCMS) mouse model was used to screen for antidepressant drug candidates. According to Figure $1 \mathrm{~B}$, the nest building score of vehicle group was significantly lower than that of the normal group (nonUCMS group, $\mathrm{p}<0.01$ ) which meant the UCMS mice have appeared the symptoms of depression. Furthermore, the results showed that the time of latency to groom of vehicle group was dramatically increased than that of normal group $(\mathrm{p}<0.01)$ while the grooming frequency and time of grooming were significantly decreased when compared to the normal group $(\mathrm{p}<0.01)$ (Figure 1C-E). These results indicated that the UCMS model has been successfully established in the paper. The results showed genistein could obviously increase the nest building score, grooming frequency and time of grooming, while decrease the time of latency to groom compared to the vehicle group $(\mathrm{p}<0.01)$ (Figure $1 \mathrm{C}-\mathrm{E})$. These data indicated genistein could improve the depressive symptoms of the UCMS-treated mice.

Besides, we also investigated the effect of gender on the results of nest building test and splash test. According to Figure $1 \mathrm{~F}$, the results showed there was no difference between male and female mice in the test results $(\mathrm{p}>0.05)$. Thus, it indicates that genistein could improve depression of the UCMS mice no matter male or female.

\section{Genistein decreases miR-221/222 but increases $\mathrm{Cx} 43$ expression levels in vivo}

The mRNA expression of miR-221/222 and the protein lev- 


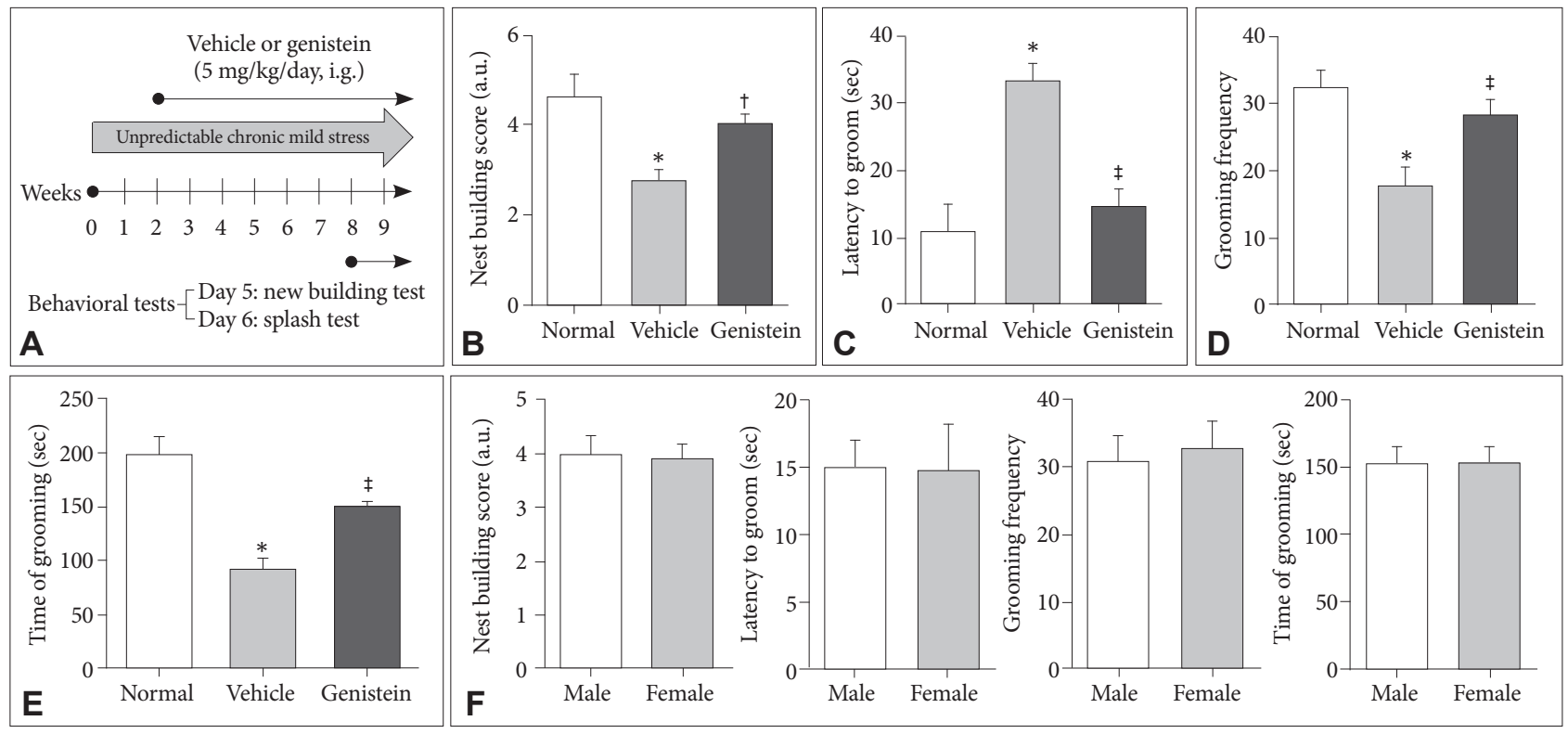

Figure 1. Genistein improves depression of UCMS model mice. A: Experimental design. B-E: The nest building test and splash test results of mice treated with different methods. F: The analysis of the impact of gender on the test results. ${ }^{*} p<0.01$ compared with the normal group, $\dagger p<0.05$ and $\neq p<0.01$ compared with the vehicle group.
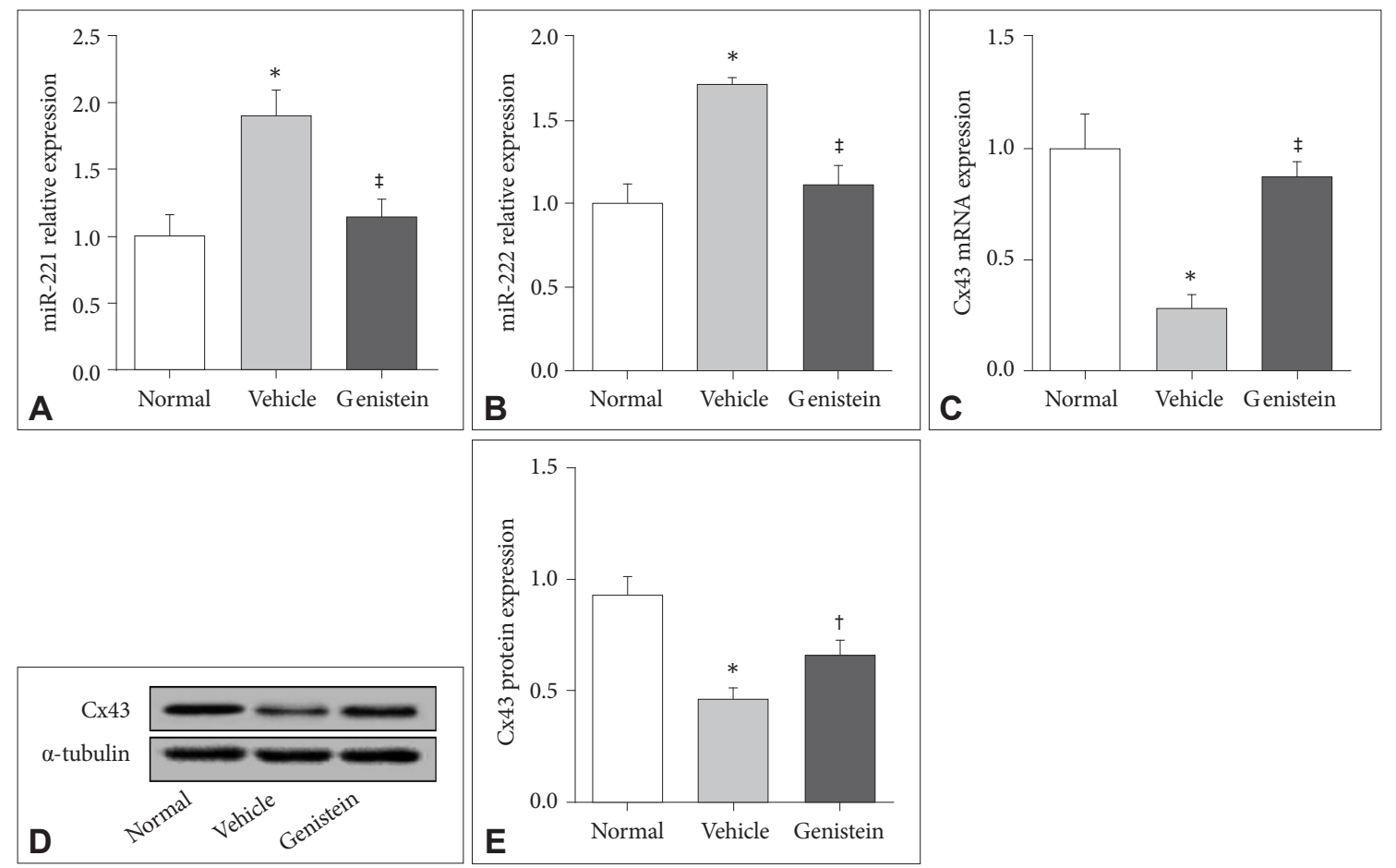

Figure 2. Genistein reduces the expression of miR-221/222 and increased the expression of Cx43. A and B: The expression of miR-221/222 in the prefrontal cortex of the mice in different groups. C: The mRNA expression of Cx43 in the prefrontal cortex of different groups. D and E: The protein level of $\mathrm{Cx} 43$ in the prefrontal cortex of different groups. ${ }^{*} p<0.01$ compared with the normal group, ${ }^{\dagger} p<0.05$ and $\neq p<0.01$ compared with the vehicle group.

el of Cx43 in mice treated with non-UCMS (normal), UCMS (vehicle) and UCMS (genistein) were detected according to the qRT-PCR and western blot analysis. The results showed that the miR-221/222 cluster was significantly up-regulated in UCMS-treated mice $(\mathrm{p}<0.01)$ (Figure $2 \mathrm{~A}$ and $\mathrm{B}$ ) and genistein could significantly inhibit the expression level of miR-221/222 in UCMS-treated mice $(\mathrm{p}<0.01)$ (Figure $2 \mathrm{~A}$ and $\mathrm{B})$. According to the results (Figure $2 \mathrm{C}$ and $\mathrm{D}$ ), the $\mathrm{mRNA}$ and protein expression levels of $\mathrm{Cx} 43$ in vehicle group were obviously lower than those in normal group $(\mathrm{p}<0.01)$, but significantly in- 
creased in the genistein group $(\mathrm{p}<0.01)$. These results indicated the up-regulation of miR-221/222 and down-regulation of Cx43 in UCMS-induced depression and genistein could increase the expression level of $\mathrm{Cx} 43$ but decrease the expression levels of miR-221/222 in UCMS-treated mice which meant genistein might improve depression through regulation of miR221/222 and Cx43.

\section{Genistein decreases miR-221/222 but increases $\mathrm{Cx} 43$ expression levels in vitro}

The U87-MG cells were incubated with genistein $(10 \mu \mathrm{M})$ for $72 \mathrm{~h}$ and then detected the mRNA expression of miR221/222 and the protein level of Cx43. The results showed that genistein could significantly inhibit the expression level of miR-221/222 but increase the expression level of $\mathrm{Cx} 43$ when compared to the vehicle control $(\mathrm{p}<0.01)$ (Figure 3$)$. The results were consistent with those in vivo which indicated genistein could really decrease the expression levels of miR221/222 but increase the expression level of Cx43.

\section{The $\mathrm{Cx} 43$ is a direct target gene of miR-221/222}

To test whether miR-221/222 directly targets Cx43, we measured the miR-221 and miR-222 expressions in U87-MG cells treated with As-miR-221 and As-miR-222, respectively. According to Figure 4A, it showed that the expression levels of miR-221 and miR-222 were both significantly lower than those in control group (UCMS-mice without AS-221/222, p< 0.01 ), while the western blot analysis showed the protein expression of $\mathrm{Cx} 43$ was dramatically increased when compared to the control $(\mathrm{p}<0.01)$ (Figure $4 \mathrm{~B})$. The results indicated there was an inverse correlation between miR-221/222 and $\mathrm{Cx} 43$. Furthermore, the luciferase reporter assay was used to verify whether $\mathrm{Cx} 43$ is a direct target of miR-221/222 by cotransfection of miR-221/222 and a luciferase reporter plasmid containing the 3'-UTR of $\mathrm{Cx} 43$. The results indicated miR-221/222 might bind to the complimentary DNA sequence on 3'-UTR of Cx43 gene (Figure 4C). Consistent with the binding data, a decrease in relative luciferase activity was shown when the Cx43 was co-transfected with the miR-221/222 (both
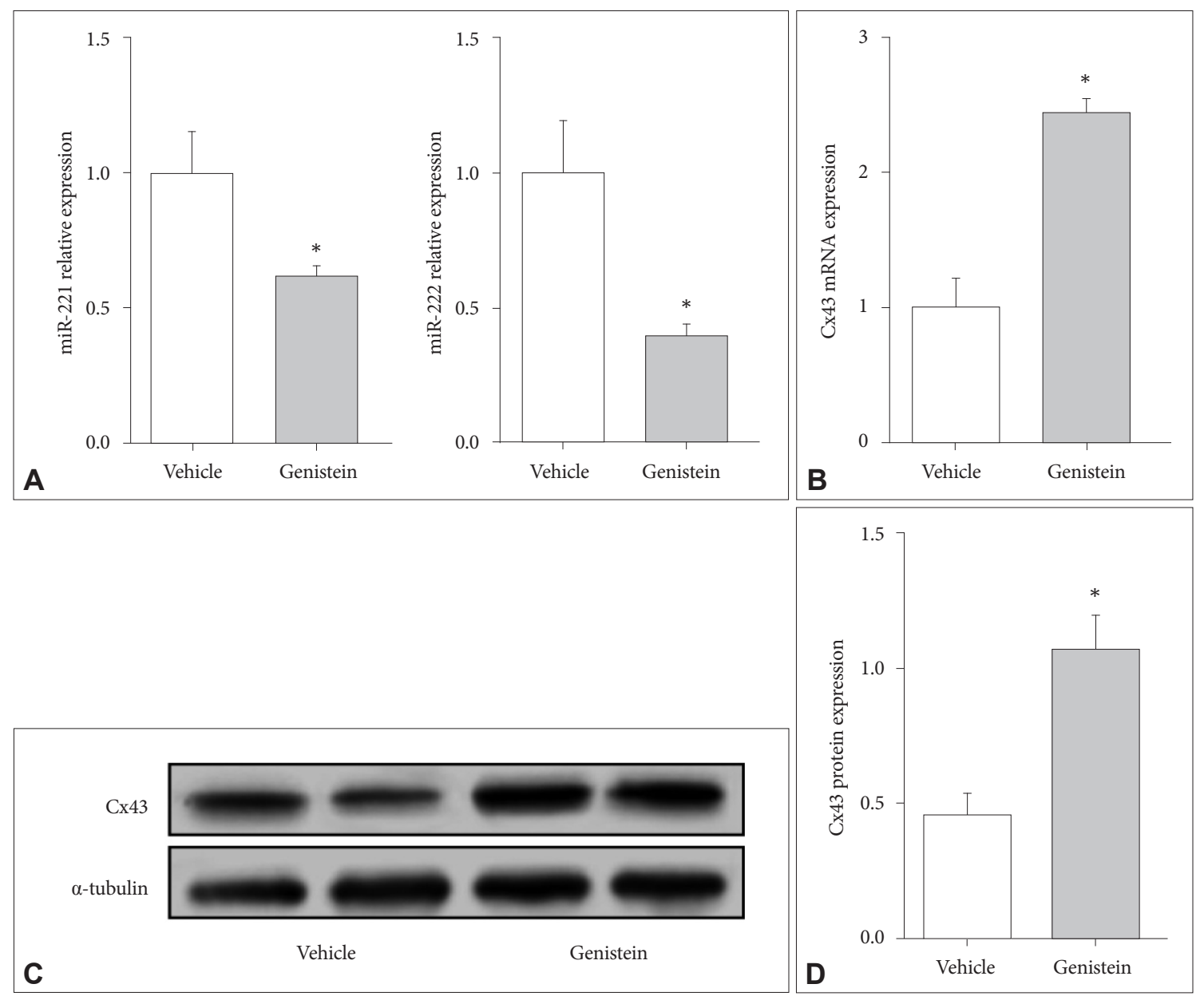

Figure 3. Genistein decreases the expression level of miR-221/222 in human astrocytoma and increases the expression level of Cx43. A: The expression of miR-221/222 in cells with different treatments. B: The mRNA expression of Cx43 in cells treated with different methods. $\mathrm{C}$ and $\mathrm{D}$ : The protein level of $\mathrm{Cx} 43$ in cells of different groups. ${ }^{*} \mathrm{p}<0.01$. 

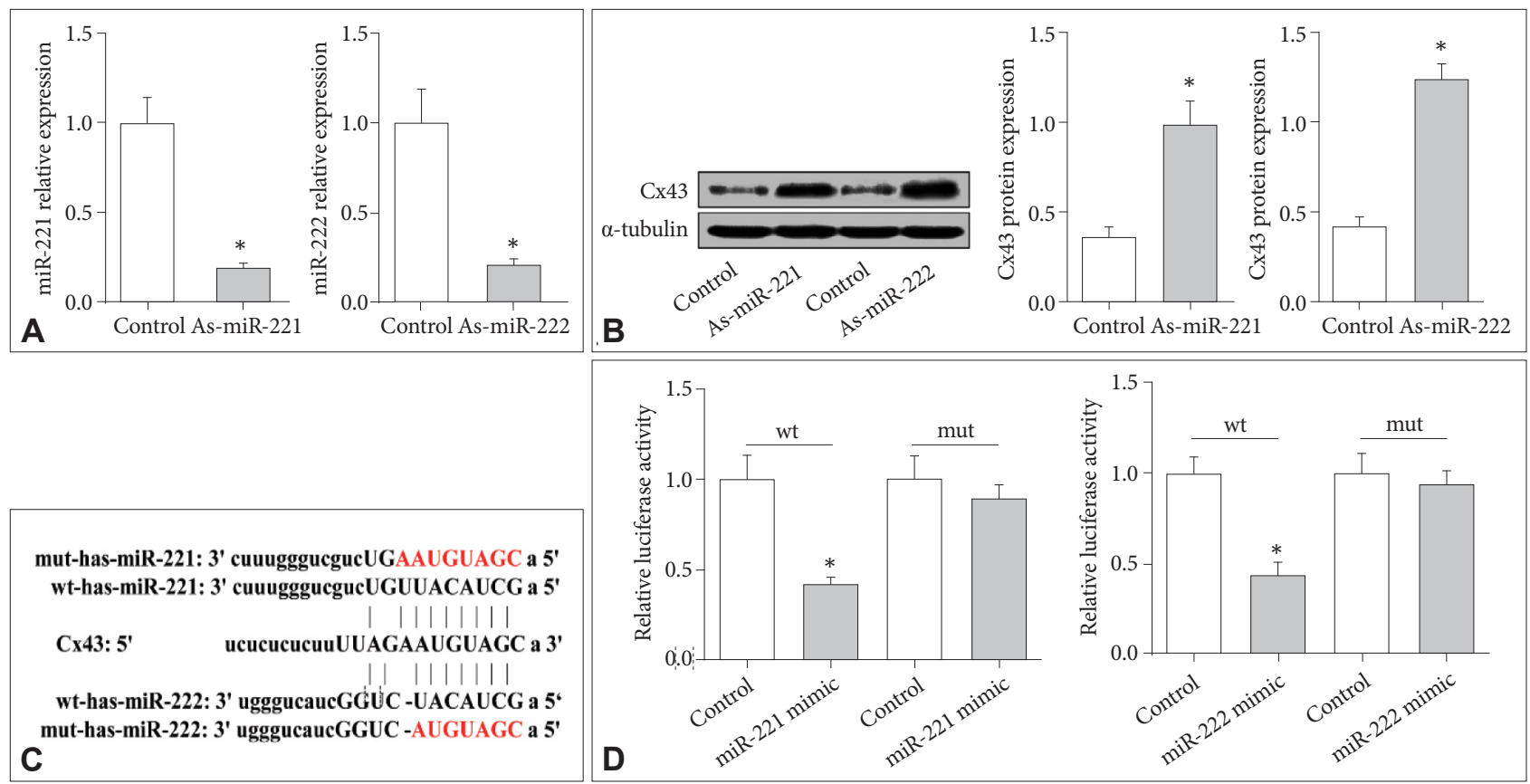

Figure 4. MiR-221/222 directly targets Cx43 in U87-MG cells. A: The relative mRNA levels of miR221/222 in cells treated with AsmiR221/222. B: The protein level of Cx43 in U87-MG cells when treated with As-miR221/222. C: The binding sites of miR-221/222 and Cx43. D: The result of dual luciferase reporter assay. ${ }^{*} p<0.01$.

$\mathrm{p}<0.01)$. These results suggest that the Cx43 3'-UTR is the functional target site for miR-221/222.

\section{DISCUSSION}

Major depression is a serious disorder that has enormous consequences for the quality of life, and is one of the most prevalent forms of mental illness. ${ }^{17}$ Patients suffered from major depression have high rates of morbidity and mortality, with profound economic and social consequences. ${ }^{18}$ Moreover, the major depression not only affects $5 \%$ of the population, but also the numbers are increasing every year. Thus, it is necessary to find new agents and therapeutics.

For the purpose above, we first performed in vivo and in vitro study to test the effect of genistein on major depression and investigate the possible mechanism of it. To confirm and verify whether genistein could improve depression, the unpredictable chronic mild stress (UCMS) mice model of depression was used to identify genistein treatments for this condition. According to the results of Figure 1, the mice treated with 10 $\mu \mathrm{M}$ genistein got the higher scores, more time of grooming and more times of grooming frequency while less time of latency to groom than those of vehicle group. The results confirmed genistein could improve the depressive symptoms of the UCMS treated mice. Briley et al. ${ }^{19}$ reported that it was a clinically and biologically heterogeneous disorder, with 10$30 \%$ of women and $7-15 \%$ of men likely to suffer from de- pression in their life time. It means the morbidity of depression among men is nearly half of that of women, however, there is no obvious difference between male and female according to Figure 1F.

Then we investigated the miR-221/222 expression and the mRNA and protein levels of Cx43 in UCMS-treated mice and U87-MG cells treated with genistein. MiRNAs are encoded in the genomes of all multicellular organisms and can be transcripted from either an intergenic cluster or single genetic regions..$^{20}$ The miR-221 and miR-222 were reported to be related to depression. ${ }^{9,11,21}$ The $\mathrm{Cx} 43$ has been identified as a depressive suppressor and major component for the establishment of gap junction intercellular communication (GJIC) in glial cells, which is frequently reduced or deleted in highgrade gliomas. ${ }^{14,15}$ According to Figures 2 and 3, the expression levels of the miR-221 and miR-222 were significantly reduced while $\mathrm{Cx} 43$ expression was up-regulated in UCMStreated mice and U87-MG cells when treated with genistein. These results showed that genistein might improve major depression through suppressing miR-221/222 or increased the expression level of $\mathrm{Cx} 43$.

Besides, the results also indicated that the expression levels of miR-221/222 were inverse correlation with those of $\mathrm{Cx} 43$ in depressive cells and mice. According to the bioinformatic analysis, Cx43 may be one of the target genes of miR-221/222. Thus, we investigated whether $\mathrm{Cx} 43$ is a target gene of miR221/222 in the present study. We transfected As-miR-221/222 
into U87-MG human astrocytoma cells and the expression of the miR-221/222 cluster and protein level of Cx43 were detected by qRT-PCR and western blot analysis. Luciferase reporter assays were exploited to confirm $\mathrm{Cx} 43$ as a target gene of miR-221/222. According to Figure 4, we found that the protein level of $\mathrm{Cx} 43$ was significantly reduced while miR221/222 expression was down-regulated in U87-MG cells transfected with As-miR-221/222. Moreover, the luciferase reporter assay verified that $\mathrm{Cx} 43$ is a target gene of miR-221/222. Thus, the results indicated that genistein could improve major depression via inhibiting the expression level of miR-221/222, at least in part, by targeting $\mathrm{Cx} 43$.

In summary, the unpredictable chronic mild stress model in mice was established to study the etiological and developmental components of major depression, and to screen for antidepressant drug candidates. Genistein could significantly improve the major depression no matter male or female according to the results. And the mechanism of the improvement effect of genistein on major depression was the down-regulation of miR-221/222 and then targeting Cx43. Thus, miR$221 / 222$ may be as an early diagnostic biomarker and genistein may be as a novel therapeutic drug of major depression.

\section{Acknowledgments}

This research was supported by Zhejiang Provincial Natural Science Foundation of China (Grant No.: LY16H160044, GF18H160085), Science and Technology Plan of Zhejiang Province, China (Grant No.: 2018251342), Zhejiang Traditional Chinese Medicine Science and Technology Project (Grant No.: 2015ZA134), and Northern Regional Special Disease Center of Zhejiang Province Fund and Hangzhou Key Disciplines Fund.

\section{REFERENCES}

1. Alvarez-Saavedra M, Antoun G, Yanagiya A, Oliva-Hernandez R, Cornejo-Palma D, Perez-Iratxeta C, et al. miRNA-132 orchestrates chromatin remodeling and translational control of the circadian clock. Hum Mol Genet 2011;20:731-751.

2. Anacker C, Zunszain PA, Carvalho LA, Pariante CM. The glucocorticoid receptor: pivot of depression and of antidepressant treatment? Psychoneuroendocrinology 2011;36:415-425.

3. Kageyama A, Sakakibara H, Zhou W, Yoshioka M, Ohsumi M, Shimoi $\mathrm{K}$, et al. Genistein regulated serotonergic activity in the hippocampus of ovariectomized rats under forced swimming stress. Biosci Biotechnol Biochem 2010;74:2005-2010.

4. Marini H, Bitto A, Altavilla D, Burnett BP, Polito F, Di Stefano V, et al. Efficacy of genistein aglycone on some cardiovascular risk factors and homocysteine levels: a follow-up study. Nutr Metab Cardiovasc Dis
2010;20:332-340.

5. Atteritano M, Mazzaferro S, Bitto A, Cannata ML, D’Anna R, Squadrito $\mathrm{F}$, et al. Genistein effects on quality of life and depression symptoms in osteopenic postmenopausal women: a 2-year randomized, doubleblind, controlled study. Osteoporos Int 2014;25:1123-1129.

6. Baffa A, Hohoff C, Baune BT, Muller-Tidow C, Tidow N, Freitag C, et al. Norepinephrine and serotonin transporter genes: impact on treatment response in depression. Neuropsychobiology 2010;62:121-131.

7. Baudry A, Mouillet-Richard S, Launay JM, Kellermann O. New views on antidepressant action. Curr Opin Neurobiol 2011;21:858-865.

8. Baudry A, Mouillet-Richard S, Schneider B, Launay JM, Kellermann O. miR-16 targets the serotonin transporter: a new facet for adaptive responses to antidepressants. Science 2010;329:1537-1541.

9. Smalheiser NR, Lugli G, Zhang H, Rizavi H, Cook EH, Dwivedi Y. Expression of microRNAs and other small RNAs in prefrontal cortex in schizophrenia, bipolar disorder and depressed subjects. PLoS One 2014; 9:e86469.

10. Wan Y, Liu Y, Wang X, Wu J, Liu K, Zhou J, et al. Identification of differential microRNAs in cerebrospinal fluid and serum of patients with major depressive disorder. PLoS One 2015;10:e0121975.

11. Zhou R, Yuan P, Wang Y, Hunsberger JG, Elkahloun A, Wei Y, et al. Evidence for selective microRNAs and their effectors as common longterm targets for the actions of mood stabilizers. Neuropsychopharmacology 2009;34:1395-1405.

12. Oved K, Morag A, Pasmanik-Chor M, Rehavi M, Shomron N, Gurwitz D. Genome-wide expression profiling of human lymphoblastoid cell lines implicates integrin beta- 3 in the mode of action of antidepressants. Transl Psychiatry 2013;3:e313.

13. Chen Y, Zaman MS, Deng G, Majid S, Saini S, Liu J, et al. MicroRNAs 221/222 and genistein-mediated regulation of ARHI tumor suppressor gene in prostate cancer. Cancer Prev Res (Phil) 2011;4:76-86.

14. Hao J, Zhang C, Zhang A, Wang K, Jia Z, Wang G, et al. miR-221/222 is the regulator of $\mathrm{Cx} 43$ expression in human glioblastoma cells. Oncol Rep 2012;27:1504-1510.

15. Miguel-Hidalgo JJ, Wilson BA, Hussain S, Meshram A, Rajkowska G, Stockmeier CA. Reduced connexin 43 immunolabeling in the orbitofrontal cortex in alcohol dependence and depression. J Psychiatr Res 2014;55:101-109.

16. Nollet M, Le Guisquet AM, Belzung C. Models of depression: unpredictable chronic mild stress in mice. Curr Protoc Pharmacol 2013;Chapter 5:Unit 5.65.

17. Abelaira HM, Reus GZ, Neotti MV, Quevedo J. The role of mTOR in depression and antidepressant responses. Life Sci 2014;101:10-14.

18. Busch Y, Menke A. Blood-based biomarkers predicting response to antidepressants. Neural Transm (Vienna) 2018 [Epub ahead of print].

19. Briley M, Moret C. Present and future anxiolytics. IDrugs 2000;3:695699.

20. Avery-Kiejda KA, Braye SG, Forbes JF, Scott RJ. The expression of Dicer and Drosha in matched normal tissues, tumours and lymph node metastases in triple negative breast cancer. BMC Cancer 2014;14:253.

21. Smalheiser NR, Lugli G, Rizavi HS, Torvik VI, Turecki G, Dwivedi Y. MicroRNA expression is down-regulated and reorganized in prefrontal cortex of depressed suicide subjects. PLoS One 2012;7:e33201. 